\title{
A Educação Física na escola do vestibular: as possíveis implicações do ENEM
}

\begin{abstract}
Resumo: Vivemos um momento em que o "velho vestibular" está sendo substituído progressivamente pelo "novo ENEM" como instrumento de seleção dos candidatos ao ensino superior. Pretendemos nesse ensaio, a partir de análise dos documentos que normatizam o ENEM e da produção teórica, refletir sobre as influências exercidas pelo ENEM na educação escolar, analisando seus significados e possíveis implicações para Educação Física, visto que o exame incorporou na sua matriz de referência os conteúdos da Educação Física. A experiência vivida pelos demais componentes escolares nos mostra que a prática pedagógica do professor de Educação Física pode passar a ser determinada/influenciada pelo ENEM.

Palavras-chave: Educação Física escolar. ENEM. Prática pedagógica.
\end{abstract}

José Arlen Beltrão*

\section{INTRODUÇão}

Já há pelo menos três décadas, discute-se na Educação Física escolar a necessidade das aulas se desenvolverem para além da técnica esportiva, rompendo com tendências históricas que privilegiam o movimento corporal em detrimento do ser que se movimenta. Esse debate proporcionou avanços significativos na tentativa de superação de práticas mecanizadas, restritas ao "fazer". Contudo, nesse movimento de (re)construção das práticas pedagógicas, professores e pesquisadores se veem desafiados frente ao posicionamento da escola contemporânea, que diferentemente

\footnotetext{
*Professor, Centro de Formação de Professores, Universidade Federal do Recôncavo da
} Bahia - UFRB. Amargosa, Bahia, Brasil. E-mail: arleneducacaofisica@ufrb.edu.br 
dos indicativos presentes em boa parte da produção teórica da Educação Física escolar, e dos esforços empreendidos por seus docentes, cada vez mais privilegia os interesses do mercado, o conhecimento abstrato e a resolução de modo simplista dos problemas enfrentados na sociedade de classes.

O desenvolvimento de habilidades e competências exigidas no mercado de trabalho está presente nos documentos orientadores da educação básica, como objetivos da escola do século XXI. O acompanhamento do desempenho da "escola moderna" é feito, dentre outras formas, por avaliações nacionais. A mais conhecida, provavelmente, seja o Exame Nacional do Ensino Médio (ENEM), que nos últimos anos ganhou proporções ainda não vistas por um exame desse tipo, além de tentar compreender áreas de conhecimento comumente não presentes nos exames nacionais.

Tendo em vista a crescente importância dos exames nacionais na constituição da escola contemporânea, mais particularmente o ENEM, objetivamos com esse ensaio refletir sobre as influências exercidas pelo ENEM e pelos vestibulares sobre a educação escolar, analisando seus significados e as possíveis implicações na Educação Física escolar. Nossas reflexões foram apoiadas em pesquisas documental e bibliográfica (GIL, 1999). O percurso metodológico foi divido em dois momentos, no primeiro, selecionamos, através de buscas no portal de periódicos e no portal de teses e dissertações da $\mathrm{CAPES}^{1}$, trabalhos publicados que versavam sobre as implicações do ENEM na dinâmica curricular das escolas. Além disso, reunimos os documentos que normatizam o ENEM (BRASIL, 2011, BRASIL, 2009a, BRASIL, 2009b, BRASIL, 2000), para isso utilizamos como fonte os portais virtuais do Ministério da Educação/MEC ${ }^{2}$ e do Instituto Nacional de Estudos e Pesquisas Educacionais Anísio Teixeira/INEP ${ }^{3}$. No segundo momento, passamos a analisar esse material. Como técnica utilizamos a análise de conteúdo, que, segundo Souza Júnior, Melo e Santiago (2010), “comumente tem

\footnotetext{
${ }^{1}$ Coordenação de Aperfeiçoamento de Pessoal de Nível Superior.

${ }^{2} \mathrm{http}: / / w w w . m e c . g o v . b r$

${ }^{3}$ http://portal.inep.gov.br
}

Movimento, Porto Alegre, v. 20, n. 2, p. 819-840, abr./jun. de 2014. 
sido utilizada nas pesquisas qualitativas em Educação Física escolar. Esta consiste num recurso técnico para análise de dados provenientes de mensagens escritas ou transcritas".

Organizamos este trabalho em três seções, iniciamos com a discussão dos processos seletivos para ingresso no ensino superior, onde o ENEM passa a exercer esta função; na seção seguinte, refletimos sobre as possíveis implicações decorrentes da inclusão dos conteúdos da Educação Física escolar no ENEM e, por fim, apresentamos nossas considerações finais.

\section{As METAMORfoses e SENTIDOS do ENEM}

O vestibular há muito tempo vem sendo o dispositivo que define quem irá dar continuidade nos estudos em nível superior, e a quem se nega o direito da vida acadêmica. Sua presença é pouca questionada na sociedade, talvez por acreditarem que o mesmo seja inerente à própria educação.

Por se dizer justo e democrático, tratando todos de maneira "igual", os sujeitos não contemplados com ingresso no ensino superior assumem para si as responsabilidades do fracasso, já que tiveram as mesmas "oportunidades" dos demais. Essa é mais uma verdade neoliberal (auto)imposta, que busca desviar a atenção do foco do problema, o alijamento do direito de dar prosseguimento na vida escolar (agora escola superior), além de mascarar a situação precária da educação básica.

O vestibular reflete e reforça as diferenças encontradas na própria sociedade em que vivemos, e está alinhado com as contradições do nosso sistema de educação, que apesar do aumento do número de vagas para o ensino superior público, prioritariamente, atende às classes sociais de maior poder econômico. Os menos favorecidos ocupam um número de vagas proporcionalmente pequeno ${ }^{4}$, na maioria das vezes, em universidades com menor concorrência.

\footnotetext{
${ }^{4}$ Apesar da maioria das famílias brasileiras serem àquelas com renda de até dois salários mínimos, apenas $26,47 \%$ das vagas nas universidades federais são ocupadas por alunos dessas famílias (ANDIFES, 2011).
}

Movimento, Porto Alegre, v. 20, n. 2, p. 819-840, abr./jun. de 2014. 
O temido vestibular sempre atormentou a vida daqueles estudantes do ensino médio que almejavam a universidade, por vezes, gerando conflitos de interesses no ambiente escolar, de um lado os vestibulandos reivindicando a inserção no currículo dos conteúdos e livros cobrados nos principais vestibulares, de outro aqueles que não se viam como candidatos ao vestibular reclamando por conteúdos que abordassem os problemas do cotidiano.

A influência do vestibular e dos processos seletivos na escolarização básica vem crescendo nos últimos anos, seguindo o aumento de ofertas de vagas no ensino superior. Não é raro encontrarmos, entre os alunos, discursos do tipo "Estudo para passar no vestibular", ou entre os profissionais da educação, "Temos que atender às demandas do mercado!" "Temos que prepará-los para o mercado de trabalho"s.

Esses discursos se aproximam das explicações oferecidas por Afonso (2005, p. 25), onde esclarece que as atividades discentes forjadas por avaliações externas podem ser entendidas ou representadas como tendo características da produção mercantil, estabelecendo valor de troca, resultando em concepções alienadas "de que o trabalho escolar não é para ser apropriado por quem o realiza, mas para ser entregue a um avaliador”.

Nesse caso, a tarefa das disciplinas escolares e da escola de maneira geral de oferecer um espaço aberto, crítico e significativo aos alunos se torna limitada com a influência negativa de caráter imediatista do mercado. Os alunos veem a escola como um veículo que irá dar subsídios para que os mesmos possam enfrentar e superar as etapas sociais impostas pelo mundo do capital, nesse caso em questão o vestibular. Assim, o importante não é apreender a produção cultural da humanidade, mas adquirir as competências e habilidades exigidas nesse processo selecionador. Os alunos, pais e parte dos profissionais da educação, bastante influenciados pelo projeto liberal de educação difundido pelos meios de comunicação,

\footnotetext{
${ }^{5}$ Discurso defendido por vários professores em um seminário realizado no interior da Bahia (Amargosa - I Seminário fundamentos para construção de um referencial curricular básico para a Educação Física na rede pública estadual da Bahia - DIREC 29).
}

Movimento, Porto Alegre, v. 20, n. 2, p. 819-840, abr.jun. de 2014. 
acreditam e creditam à escola essa tarefa, "preparar o aluno para o mercado de trabalho/vestibular".

O vestibular se configura como um instrumento justificador das diferenças sociais apresentando-as apenas como individuais. Observamos que esse é o momento culminador de uma lógica que perpassa todo o sistema de ensino. Já que a escola perdeu os atrativos naturais, se distanciou do cotidiano e interesses dos sujeitos, foi necessário introduzir dispositivos artificiais que motivassem os alunos a estudar, assim as avaliações de caráter punitivo vêm ganhando espaço e importância no contexto escolar. A escola se move para e por conta das avaliações, condicionando, consequentemente, seus alunos aos processos selecionadores da sociedade capitalista.

A necessidade de introduzir mecanismos artificiais de avaliação (prova, testes etc.) foi motivada pelo fato da vida ter ficado do lado de fora da escola. Com isso, ficaram lá também os "mecanismos naturais" para a aprendizagem, obrigando a escola a lançar mão de "motivadores artificiais" - foi desenvolvido um sistema de avaliação com notas como forma de estimular a aprendizagem e de controlar o comportamento de contingentes cada vez maiores de acudiam à escola e tinham de ficar dentro delas, imobilizadas, ouvindo o professor (FREITAS, 2003, p. 28).

A lógica da avaliação não é independente da lógica da escola. Ao contrário, ela é produto de uma escola que entre outras coisas, separou-se da vida, da prática social [...] isso colocou como centro da aprendizagem a aprovação do professor, e não a capacidade de intervir na prática social. Aprender para "mostrar conhecimento ao professor" tomou lugar do "aprender para intervir na realidade" (FREITAS, 2003, p. 40).

Para melhor entendermos as influências e determinações exercidas por instrumentos avaliativos extraescolares, e conhecermos as tendências no ambiente escolar, necessitamos desvendar os sentidos e significados, nesse espaço, do ENEM, que

Movimento, Porto Alegre, v. 20, n. 2, p. 819-840, abr.jun. de 2014. 
foi criado em 1998, tendo como objetivo avaliar o desempenho da escolaridade básica (BRASIL, 2011). O exame surge como um instrumento para subsidiar políticas públicas voltadas para o ensino médio, a partir do mapeamento realizado levando em consideração os resultados de cada Estado, cidade e escola.

OENEMnasce, portanto, comouminstrumento diagnosticador, que busca "aferir o desenvolvimento de competências fundamentais ao exercício pleno da cidadania” (BRASIL, 2000, p. 1), com a pretensão de ser uma importante ferramenta de reestruturação do Ensino Médio (BRASIL, 2009a). O mesmo compõe um grupo de instrumentos externos (Provinha Brasil, Prova Brasil, Exame Nacional de Desempenho de Estudantes - ENADE), de caráter quantitativo e genérico (comparativos), centrados no produto, que fomentam a competição entre as escolas e entre os alunos, e o retorno, aos sujeitos interessados, das informações obtidas se dá perfunctoriamente, fato que dificulta a superação dos problemas. Esses instrumentos são impulsionados pela crença que o simples fato de avaliar o sistema garantirá a qualidade da Educação. A qualidade é entendida como o aumento da proficiência dos alunos nos testes, uma análise no mínimo superficial dos aspectos determinantes da educação escolar, que desconsidera as condições objetivas em que a educação, nos diferentes espaços, se desenvolve.

As avaliações externas são importantes e necessárias para se implementar e acompanhar políticas públicas em educação, desde de que desenvolvidas com metodologias adequadas que possibilitem o diálogo com as avaliações institucionais promovidas pelas unidades escolares, oferecendo informações interessantes para toda a comunidade. Entretanto, os dados do ENEM publicados e disponibilizados às escolas não subsidiam ações efetivas, visto seu caráter abstrato e a dificuldade dos profissionais das escolas interpretarem tais informações.

As políticas de avaliação centralizadas se esquecem que não basta o dado do desempenho do aluno ou do professor coletado em um teste ou questionário e seus fatores associados. É preciso que o dado seja "reconhecido" como

Movimento, Porto Alegre, v. 20, n. 2, p. 819-840, abr.jun. de 2014. 
"pertencendo" à escola. Medir propicia um dado, mas medir não é avaliar. Avaliar é pensar sobre o dado com vistas ao futuro. Isso implica a existência de um processo interno de reflexão nas escolas [...] (FREITAS et al., 2012a, p. 48).

$\mathrm{O}$ ato de avaliar não se encerra na aferição de um objeto ou na configuração do valor ou qualidade atribuída a ele. A avaliação ultrapassa a obtenção da configuração do objeto, já que deve promover uma verdadeira reflexão sobre as informações coletadas visando uma tomada de decisão. A aferição é uma ação que "congela" o objeto, diferentemente da avaliação que o direciona numa trilha dinâmica (LUCKESI, 2008).

Faz parte do senso comum entender a avaliação como sinônimo de medida ou prova, tendo como função a classificação [...]. As funções diagnóstica e formativa da avaliação educacional têm sido colocadas em segundo plano, especialmente nos últimos anos, a partir da grande valorização que se tem atribuído aos instrumentos de avaliação, por exemplo, a Prova Brasil e o ENEM, sem contar os inúmeros procedimentos de avaliação estaduais e municipais. Testes ou provas não são a avaliação de fato, mas apenas instrumentos para ela (FREITAS et al., 2012b, p. 227.

$\mathrm{O}$ que tem prevalecido nas políticas de avaliação do MEC é a mensuração do desempenho dos alunos nos diferentes testes e a construção de rankings, contribuindo com o equivocado entendimento de que mensurar é sinônimo de avaliar. Sordi e Ludke (2009, p. 319) criticam essas medidas, visto que o ciclo virtuoso da avaliação não se completa, produzindo apenas "números esquecidos em relatórios que não são suficientemente explorados e/ou apropriados pelos professores/alunos/famílias/gestores. Mas geram políticas que incidem sobre as escolas e sobre a educação, de um modo geral". Segundo as autoras, esse processo precisa ser fortemente interrogado, já que desqualifica a função social da avaliação.

Movimento, Porto Alegre, v. 20, n. 2, p. 819-840, abr.jun. de 2014. 
A forma como esses instrumentos operam sugere que suas intenções não são buscar subsídios para intervenções mais precisas e consistentes do poder público, analisando as informações coletadas na tentativa de propor ações que abranjam toda a rede e, ao mesmo tempo, ações localizadas, mas difundir nos sistemas escolares uma dada concepção de avaliação, que tem como finalidade a instalação de mecanismos que estimulem a competição entre as escolas, responsabilizando-as, em última instância, pelo sucesso ou fracasso escolar (SOUSA, 2003).

Nesse contexto, a discussão sobre o projeto pedagógico da escola vai se perdendo e, em seu lugar, são empreendidos esforços para dar conta do padrão imposto pelos processos avaliativos para melhorar a posição no ranking das escolas. Os professores são mobilizados no sentido de melhor preparar seus alunos para a realização dos exames nacionais (ZANCHET, 2005, p. 181).

Quanto à relação estabelecida entre os índices do ENEM e o mercado de trabalho, o boletim de resultados do exame não, necessariamente, guarda importância direta para o mercado, visto que as empresas não cobram/utilizam esses dados como critério para a seleção, preferem sim promover os seus próprios processos. No entanto, o mercado exerce pressão no sentido do exame incluir as competências e habilidades para o novo mundo do trabalho, essa inclusão, por sua vez, irá influenciar o desenvolvimento do ensino médio.

Vivemos um momento em que o "velho vestibular" está sendo substituído progressivamente pelo "novo ENEM" como instrumento de seleção dos candidatos ao ensino superior brasileiro7. A intenção é que o ENEM venha ser o "vestibularzão" do Brasil, sustentado no discurso neoliberal de democratização do

\footnotetext{
${ }^{6}$ Designação dada ao exame (novo ENEM) pelo Ministério da Educação - MEC, após reformulação sofrida em 2009, que, dentre as proposições, possibilitou sua utilização como forma de seleção unificada nos processos seletivos das universidades públicas brasileiras.

${ }^{7}$ Segundo o Ministério da Educação (BRASIL, 2011), cerca de 500 universidades já usam o resultado do exame como critério para o ingresso no ensino superior, seja completando ou substituindo o vestibular. Além disso, é utilizado como critério na obtenção de bolsa do Programa Universidade Para Todos (PROUNI).
}

Movimento, Porto Alegre, v. 20, n. 2, p. 819-840, abr./jun. de 2014. 
ensino superior. Com isso, o ENEM, além de incorporar a lógica própria do vestibular, incorpora sua função histórica de selecionar.

Não podemos negar que as questões que compõem o teste do ENEM representam um avanço em relação aos modelos avaliativos da maioria dos vestibulares do Brasil. Os alunos são postos a resolverem situações problemas mais próximas do seu cotidiano, exigindo mais do raciocínio lógico e da interpretação, do que da memorização de fatos, fórmulas e acontecimentos.

A avaliação (ENEM) baseia-se na concepção construtivista e piagetiana de desenvolvimento cognitivo e de ensino, as quais valorizam a autonomia intelectual do(a) discente, o(a) qual aprende aprendendo. Está configurada a partir de competências transversais como constatar, interpretar, compreender, explicar, solucionar e outras; o(a) discente é colocado(a) diante de problematizações contextualizadas e de caráter interdisciplinar. [...] O conteúdo programático do novo Enem diverge, entre outros aspectos existentes nos principais vestibulares do país, na cobrança de conhecimentos sobre teatro, Educação Física, artes e outras matérias marginalizadas pela maioria das escolas públicas e privadas brasileiras (KOHL, 2010, p.3).

No entanto, com essa mudança, o exame ganha uma conotação mais selecionadora, suas funções diagnóstica e formativa da avaliação educacional (se um dia houve) vão sendo substituídas em decorrência dos novos sentidos atribuídos, transformando-o em um fim em si mesmo.

A escola, por sua vez, já sente/incorpora a metamorfose do ENEM, agora redimensionado, atingindo os interesses de um público maior, implicando em transformações na dinâmica curricular das escolas, que pressionadas pelos índices, pelo novo desejo dos alunos e por se tratar de um instrumento/orientação oficial, passa a "preparar seus alunos para o ENEM", em um processo que poderíamos chamar de "vestibularização da escola".

Movimento, Porto Alegre, v. 20, n. 2, p. 819-840, abr./jun. de 2014. 
É evidente que esse não é o único fator determinante no desenvolvimento do currículo escolar, e ainda, sua ação, como qualquer outra, encontra focos de resistência, contudo, o ENEM se une a outros expedientes na materialização de um projeto educacional.

Nesse contexto, não nos esqueçamos de que aumenta a ocorrência de fraudes pedagógicas (BARRIGA, 2008), caracterizadas por preparações técnicas para a prova, quase sempre desenvolvidas pela "indústria dos cursinhos", em nome da eficácia pedagógica, onde se identifica as formas de resolução das questões das provas anteriores, fragmentando mais ainda o processo de ensino e aprendizagem.

Não podemos negar que "a escola é, ela mesma, um reflexo do seu tempo" (FREITAS, 2004, p. 149). Em uma sociedade de classes, como não poderia ser diferente, os diferentes projetos educacionais atendem a interesses diversos, nesse caso específico, o projeto dominante é sustentador e disseminador das ideias neoliberais, que tem como finalidade "um projeto que vê o ser humano como um objeto a mais no espaço da produção. Um ser que não define seu sentido da vida nem seu projeto social, mas que se insere em um projeto preestabelecido para ele" (BARRIGA, 2008, p. 51).

O afastamento dos sujeitos interessados da discussão coletiva de elaboração de projetos educacionais dificulta a apreensão dos conhecimentos da sua própria realidade, num processo que favorece a homogeneidade cultural e a dominação das classes menos favorecidas (ESTEBAN, 2008).

\section{0 enquadramento da Educação Física frente À VESTIBULARIZAÇÃO DA ESCOLA E SUA INCLUSÃO NO ENEM}

Como o objeto de estudo da Educação Física Escolar sempre se distanciou dos saberes exigidos nos vestibulares, seu espaço no ambiente escolar, por muito tempo, ficou deslocado da lógica avaliativa da escola. Com a incorporação dos conteúdos próprios da

Movimento, Porto Alegre, v. 20, n. 2, p. 819-840, abr.jun. de 2014. 
Educação Física na matriz de referência do novo ENEM, na área de linguagens, códigos e suas tecnologias, onde o aluno deve ser competente para "Compreender e usar a linguagem corporal como relevante para a própria vida, integradora social e formadora da identidade" (BRASIL, 2009b, p. 2), este componente passa a estar propenso às determinações típicas da "vestibularização" da escola.

A inclusão da Educação Física no ENEM é vista por alguns (KOHL, 2010, MELO; FERRAZ, 2007) como a possibilidade deste componente, finalmente, conseguir o reconhecimento da comunidade escolar e deixar de ser um componente curricular marginalizado, de "segunda categoria", passando a receber tratamento igualitário. Este posicionamento surge do entendimento que a Educação Física deve se aproximar do modo que as demais disciplinas operam no ambiente escolar, já que estas, dentre outros artifícios, como forma de legitimá-las, fazem uso de exames no processo de motivação de seus alunos (FREITAS, 2003). Assim, o debate sobre a legitimidade da Educação Física ganha uma velha nova roupagem, velha por poder se render ao status quo, nova por se tratar de um fenômeno não vivido ainda pela área, que já se sustentou pela manutenção e promoção da saúde, pelo conceito de aptidão física e pelo esporte na escola (BRACHT, 2001).

Entre os que veem o exame como a salvação da Educação Física, e aqueles que desconfiam de suas finalidades, estão o aparato midiático que divulga o ENEM como o redentor da classe trabalhadora, os livros didáticos que tratam das questões do exame e referenciam a importância do trabalho pedagógico na direção da contextualização dos conteúdos apontada pelo exame, fatos que, inevitavelmente, atingem a prática pedagógica dos professores. "Nessas circunstâncias, as avaliações nacionais deixam os professores de 'pés e mãos amarradas' e invadem o espaço da sala de aula, direcionando e interferindo no trabalho docente. Essa situação pode ser percebida em todos os níveis de ensino" (ZANCHET, 2007, p. 57).

Busca-se reduzir e subordinar a prática do ensinoaprendizagem à exterioridade, a partir da adoção de regras e da utilização de um suporte material

Movimento, Porto Alegre, v. 20, n. 2, p. 819-840, abr.jun. de 2014. 
(livros, mídia institucional, parâmetros) que se quer prescritivo, estandardizado (grifo nosso) e, por isso, mesmo passível de ser classificado, mensurado e comparado, sempre com a finalidade de atingir metas (LOPES; LOPEZ, 2010, p. 97).

Nesse sentido, perceba que o ENEM, veladamente, vem se tornando um instrumento de controle/regulação do trabalho docente na materialização da reestruturação do ensino médio, conforme anunciado em sua matriz de referência, seguindo a ordem do capital.

O ENEM está associado a outros documentos normatizadores do ensino médio na reorganização desse nível de ensino, como é o caso dos Parâmetros Curriculares Nacionais (PCN) do ensino médio (BRASIL, 1999):

Até o presente, a organização curricular do Ensino Médio brasileiro teve como referência mais importante os requerimentos do exame de ingresso à educação superior. A razão disso, fartamente conhecida e documentada, pode ser resumida muito simplesmente: num sistema educacional em que poucos conseguem vencer a barreira da escola obrigatória, os que chegam ao Ensino Médio destinam-se, em sua maioria, aos estudos superiores para terminar sua formação pessoal e profissional (BRASIL, 1999, p. 64).

Veja que os PCN do ensino médio anunciavam a intenção de romper com o modelo propedêutico de educação desenvolvido até então, no entanto, contraditoriamente, passados treze anos, com o aumento de matrículas no ensino médio, a expansão do ensino superior, esse quadro nada ou pouco mudou, inclusive com indícios de intensificação da influência dos exames como referência para esse nível de ensino, e fortalecimento do ENEM como instrumento regulador.

Lopes e Lopez (2010) destacam a importância do ENEM na constituição de um novo ensino médio e sua influência no processo de ensino e aprendizagem:

Movimento, Porto Alegre, v. 20, n. 2, p. 819-840, abr./jun. de 2014. 
[...] o ENEM, como um sistema avaliativo que condensa os princípios da Reforma Educacional do Ensino Médio brasileiro, se constitui como um dispositivo que entrelaça e interpenetra o processo de ensino e aprendizagem em múltiplos níveis [...] Pelos efeitos que produz nas políticas de currículo, os discursos associados a esse exame constituem um contexto de influência para outras ações curriculares e também para outros sistemas de avaliação (LOPES; LOPEZ, 2010, p. 104).

Como apontado por Fonseca (2010), em pesquisa realizada no ambiente escolar, toda a escola sofre influência do ENEM, assim, provavelmente, não será diferente com a Educação Física, visto que o exame traz a necessidade de adaptação da escola, como podemos ver abaixo:

Com a pesquisa realizada com gestores, pedagogos e professores, apreende-se que o ENEM, apesar de inúmeros questionamentos citados pelos professores, tem a aprovação e aceitação da escola e tem provocado mudanças na escola [...] Afirmam que uma avaliação como o ENEM, faz a escola se questionar e rever sua prática. A avaliação incomoda e isto pode gerar revisão das práticas (FONSECA, 2010, p. 163).

[...] o ENEM traz a necessidade da adaptação da escola. A escola deve mudar e criar alternativas que possibilitem a melhoria de seu desempenho no exame. [...] Sob essa perspectiva, a pesquisa indica que a escola responde ao ENEM, essencialmente, com a prática da avaliação (FONSECA, 2010, p. 164).

Como as demais disciplinas, o professor de Educação Física sofrerá pressão para modificar seu modo de ensinar e avaliar, tanto dos gestores das escolas, quanto dos pais e mães dos alunos. O Exame acaba promovendo mecanismos complementares de controle, associados aos resultados obtidos pela escola. Essas alterações foram evidenciadas por Silva (2012):

Da análise que efetivamos sobre as influências do

ENEM no trabalho pedagógico dos professores e

Movimento, Porto Alegre, v. 20, n. 2, p. 819-840, abr.jun. de 2014. 
no currículo observamos que as mudanças foram sentidas, principalmente em sua maneira de ensinar e avaliar. [...] Ao tomar forma de regulação, a avaliação altera a maneira do professor ensinar. Assim, tais políticas têm provocado, no ensino brasileiro, uma onda de mudanças [...] (SILVA, 2012, p. 193).

Nesse contexto, a Educação Física passa a ser de maneira direta vítima dessa ofensiva neoliberal, como os demais componentes, pressionada a trabalhar no sentido de promover uma Educação de "qualidade", uma Educação eficaz.

A adesão dos professores aos parâmetros instituídos pelo ENEM ocorre, segundo Zanchet (2007), na maioria das vezes, sem uma reflexão aprofundada dos seus pressupostos, sentidos e intenções. O agir responsável e autônomo do professor fica cada vez mais condicionado pelos limites estipulados, previamente, por um currículo nacional, e, posteriormente pelas avaliações de desempenho de seus alunos. Esse processo tende a responsabilizar os professores pelo insucesso dos discentes.

Não podemos deixar de considerar que fatores como classe social dos alunos que frenquentam a escola, localização da escola e acesso aos meios de comunicação podem determinar o grau de influência que o ENEM venha a exercer na dinâmica curricular de uma disciplina/componente, conforme destaca Freitas (2007, p. 162):

[...] é provável que o grau de atenção a ele (ENEM) seja bem diferente em distintas localidades, sistemas de ensino e escolas. É possível que maiores oportunidades de acesso a informações publicadas sobre seus resultados (como acesso à internet, a jornais e revistas), uma mais elevada

\footnotetext{
${ }^{8} \mathrm{O}$ conceito de "Educação de qualidade" disseminado pelo governo está alinhado com a concepção da Unesco, que a defini, principalmente, a partir dos resultados educativos, representados pelo desempenho do aluno, envolvendo ainda a relação entre os recursos materiais e humanos e os alunos atendidos, uma tentativa clara de encarar a Educação através de números. "Destaca, ainda, que a qualidade da educação articula-se a avaliação, na medida em que afirma que, em que pese a complexidade do termo, ela pode ser definida a partir dos resultados educativos expressos no desempenho dos estudantes" (BRASIL, 2007, p. 8)
}

Movimento, Porto Alegre, v. 20, n. 2, p. 819-840, abr./jun. de 2014. 
expectativa dos estudantes de virem a ingressar no ensino superior e uma maior concorrência no acesso a esse ensino sejam fatores que influenciem uma maior atenção da parte de alunos e professores a esse exame.

Segundo Afonso (2005), exames como o ENEM se apresentam como instrumentos de regulação do currículo escolar. Nesse sentido, esses conteúdos podem passar a receber uma maior atenção de professores e alunos, restringindo o espaço das outras manifestações, inclusive aquelas emergentes, que surgem, por exemplo, nos diferentes espaços de educação informal e não formal. A Educação Física escolar talvez seja o componente curricular que melhor dialogue com os outros espaços de educação, tematizando em suas aulas manifestações populares como o maculelê, a capoeira, a luta marajó, o fandango, o futebol de rua, os diversos jogos populares, que no ambiente escolar recebem uma leitura científica, iniciativa que valoriza os saberes locais ao mesmo tempo em que oferece instrumentos teórico-práticos para a atuação crítica e consciente dos alunos na sociedade.

A experiência vivida por outros componentes curriculares (FONSECA, 2010, LOPES; LOPEZ, 2010, SILVA, 2012, SOUSA, 2003, ZANCHET, 2007) sugere que a dinâmica curricular da Educação Física sofrerá influência no sentido da homogeneização do currículo. Caso isso se confirme, um impasse será instalado, já que muitos Estados têm orientações curriculares que se diferem (RIO GRANDE DO SUL, 2009, MINAS GERAIS, 2005, PERNAMBUCO, 2008, PARANÁ, 2008), com isso, gerando questionamentos do tipo: O professor deve privilegiar o tratamento dos conteúdos que "caem" no ENEM ou abordar os conteúdos previstos nas orientações curriculares Estaduais?

Nessa nova conjuntura, diferentemente daqueles que veem o ENEM como meio de garantir espaço e importância à Educação Física no ambiente escolar, entendemos que devemos ficar atentos à intensificação da sedução para que os professores de Educação Física adotem práticas pedagógicas que se desenvolvem a partir

Movimento, Porto Alegre, v. 20, n. 2, p. 819-840, abr.jun. de 2014. 
daquilo que supostamente vai "cair na prova". Isso levaria, no mínimo, ao empobrecimento do componente, que passaria a desconsiderar a diversidade das manifestações da cultura corporal das várias regiões brasileiras, visto com essa tendência o possível engessamento do currículo.

Diretrizes curriculares não devem ser confundidas com padronização de currículos, aquelas agem no sentido de orientar e nortear o desenvolvimento do componente curricular, não restringindo a inovação pedagógica, o tratamento dos conhecimentos locais, a diversidade regional. Essas iniciativas se veem coagidas pela força que o ENEM ganha na sociedade brasileira.

A legitimação da Educação Física por meio deste instrumento pode alimentar uma tendência de privilégio à dimensão "intelectual" do educando, em detrimento ao fazer, ao vivenciar, assim como vemos em outras áreas, já presentes nos processos de seleção, visto que esses processos, geralmente, negligenciam a dimensão prática dos conteúdos. A Educação Física passaria a falar sobre os esportes, jogos, danças, lutas, ginásticas e outras práticas corporais, e correria o risco de perder aquilo que a caracteriza, o fazer corporal. O desafio histórico de romper com a dicotomia entre teoria prática, de ir para além do fazer irrefletido, incorporando ao tratamento pedagógico os conhecimentos históricos, sociológicos, econômicos das manifestações da cultural corporal, estaria posto do outro lado do pólo. O desafio agora seria convencer os alunos, mesmo pressionados pela lógica escolar e pelas competências exigidas no ENEM, da importância da experiência corporal para suas vidas.

A Educação Física, diferentemente de conformar sua prática pedagógica ao exame, deve possibilitar aos discentes condições para que os mesmos possam se apropriar dos conhecimentos científicos da cultura corporal, confrontando-os com os saberes que eles trazem do seu cotidiano, levando-os a fazer uma leitura crítica da realidade, a experimentar e transformar as práticas corporais. Nesse sentido, deixaremos de tratar os conteúdos superficialmente,

Movimento, Porto Alegre, v. 20, n. 2, p. 819-840, abr./jun. de 2014. 
o pensamento dos alunos dará um salto qualitativo, de uma forma sincrética a uma sintética.

\section{Considerações Finais}

O sistema de avaliação da educação básica brasileira, o qual o ENEM faz parte, age no sentido de estimular a competição entre os alunos, e entre as escolas, entendendo que a competição gera qualidade. O Estado alimenta essa competição, objetivando a qualidade, quando oferece bônus às escolas e aos professores, e vagas no ensino superior aos alunos. Com essas iniciativas, o Estado se consolida como Estado-regulador.

As mudanças/metamorfoses do ENEM levaram esse exame a incorporar as funções e a lógica do vestibular, e com um discurso democrático busca se distanciar das críticas historicamente recebidas pelos vestibulares, transferindo, cada vez mais, o ônus da culpa aos estudantes e professores. Esse processo esconde as péssimas condições da educação básica e pequeno número de vagas no ensino superior. Essas e outras questões levantadas nesse trabalho indicam a necessidade que temos (universidade escola básica - sociedade) em discutir como a Educação está se desenvolvendo em nosso país.

Destacamos que, até o momento, não há trabalhos publicados que tenham como objeto de estudo os impactos no cotidiano escolar promovidos pela inclusão dos conhecimentos da cultura corporal no ENEM, por ser esse fato algo muito recente e o ambiente escolar um espaço multideterminado, podemos apenas apontar as possíveis implicações na dinâmica curricular da Educação Física escolar, tendo como parâmetro a experiência vivida por outras áreas de conhecimento, que sofrem a mais tempo influência do ENEM, principalmente na seleção e tratamento dos conteúdos.

Como evidenciam alguns trabalhos (FONSECA, 2010, LOPES; LOPEZ, 2010, SILVA, 2012, SOUSA, 2003, ZANCHET, 2007), o ENEM apresenta-se como um potencial condicionador

Movimento, Porto Alegre, v. 20, n. 2, p. 819-840, abr.jun. de 2014. 
do currículo escolar, podendo, por sua vez, promover alterações no ensino da Educação Física nas escolas, realinhando-a com a lógica imediatista e utilitarista do vestibular. Consideramos que o processo de ensino e aprendizagem deve ter como princípio e fim a prática social, a fim de proporcionar condições para que o sujeito desenvolva suas potencialidades humanas, e possa se posicionar criticamente frente aos acontecimentos sociais. Por isso, o currículo escolar deve ser construído coletivamente, e os conteúdos escolares devem emergir da realidade concreta e dinâmica dos alunos, e não a partir de fatores externos. Nesse sentido, é necessário, para a materialização de um projeto crítico, que a escola e os professores assumam posição política que coloque o aluno como sujeito de sua formação, como ser histórico que constrói sua própria história, "superando" a proposição formativa alimentada pelo ENEM, pautada no desenvolvimento de competências exigidas no mercado de trabalho, que, consequentemente, negligência o ser histórico.

A Educação Física deve se constituir como um espaço significativo para se estudar as práticas corporais, abordando os aspectos históricos, sociais, filosóficos e práticos desse campo de conhecimento, onde o aluno possa identificar os sentidos dos diversos conteúdos na sua vida. Essa tarefa demanda envolvimento e participação de professores e alunos na construção de uma Educação Física eminentemente educativa, sem, contudo, privilegiar uma ou outra dimensão do conteúdo. Historicamente privilegiamos a dimensão do fazer, dificultando a compreensão por parte dos alunos da totalidade dos conteúdos, por isso, alertamos que a possível influência do ENEM na direção de privilegiarmos os conceitos e fatos pode nos levar a problemas parecidos ao que vivemos hoje.

Por fim, entendemos que, por conta da dimensão que o exame vem ganhando na sociedade brasileira, torna-se necessário o desenvolvimento de estudos empíricos para acompanhar como alunos e professores vão se portar frente à incorporação dos conhecimentos da cultura corporal no ENEM.

Movimento, Porto Alegre, v. 20, n. 2, p. 819-840, abr./jun. de 2014. 


\begin{abstract}
La Educación Física en la escuela del examen "vestibular": las posibles implicaciones del ENEM

Resumen: Vivimos en una época en que el "viejo vestibular" está siendo substituido progresivamente por el "nuevo ENEM" como herramienta para la selección de los candidatos a la universidad. Pretendemos en ese estudio, a partir del análisis de los documentos que regulan el ENEM y del producción teórica del área, reflexionar sobre las influencias del ENEM en la educación escolar, el análisis de sus significados y posibles implicaciones para la Educación Física. La experiencia vivida por los otros componentes escolares indícanos que la práctica pedagógica del profesor de Educación Física puede empezar a ser determinada/ influenciada por el ENEM.
\end{abstract}

Palabras-clave: Educación Física escolar. ENEM. Práctica pedagógica.

\section{Physical Education in the "vestibular" exam school: the} ENEM possible implications

Abstract: We are living a moment in which the "old "vestibular"' is being changed by the "new ENEM" as the candidates selection exam to the superior school. We intent in this study, from analysis of documents that regulate the ENEM and theoretical production of the area, to reflect the influences exerted by ENEM in the school education, analyzing its meanings and possible implications to Physical Education contents of this area were incorporated to ENEM references list. The acquired experience of other school components shows that the pedagogical practice of the Physical Education teacher may begin to be determined/ influenced by the ENEM.

Keywords: School Physical Education. ENEM. Pedagogical practice.

\section{REFERÊNCIAS}

AFONSO, A. J. Avaliação educacional: regulação e emancipação. 3. ed. São Paulo: Cortez, 2005.

ANDIFES. Perfil Socioeconômico e Cultural dos Estudantes de Graduação das Universidades Federais Brasileiras. In: FÓRUM NACIONAL DE PRÓ-REITORES DE ASSUNTOS COMUNITÁRIOS E ESTUDANTIS, 2011, Brasília. [Anais...] (FONAPRACE). Brasília: TC Gráfica e Editora, 2011.

Movimento, Porto Alegre, v. 20, n. 2, p. 819-840, abr.jun. de 2014. 
BARRIGA, A. D. Uma polêmica em relação ao exame. In: ESTEBAN, M. T. (Org.). Avaliação: uma política em busca de novos sentidos. 6. ed. Petrópolis: DP, 2008.

BRACHT, V. Saber e fazer pedagógicos: acerca da legitimidade da Educação Física como componente curricular. In: CAPAROZ, F. E. (Org.). Educação física escolar: política, investigação e intervenção. Vitória-ES: Proteoria, 2001.

BRASIL. Ministério da Educação. ENEM: apresentação. Brasília: MEC, 2011.

BRASIL. Ministério da Educação. Matriz de referência do ENEM de 2009. Brasília: MEC/INEP, 2009a.

BRASIL. Ministério da Educação. Matriz de Referência de Linguagens, Códigos e suas Tecnologias. In: MATRIZ de referência do ENEM de 2009. Brasília: MEC/ INEP, 2009b.

BRASIL. Ministério da Educação. Instituto Nacional de Estudos e Pesquisas Educacionais Anísio Teixeira. Exame Nacional do Ensino Médio - ENEM: documento Básico 2000. Brasília: MEC/INEP, 2000.

BRASIL. Ministério da Educação. Instituto Nacional de Estudos e Pesquisas Educacionais Anísio Teixeira. A qualidade da educação: conceitos e definições. Série Documental (INEP), Brasília, v. 24, n. 22, p. 5-34, 2007.

BRASIL. Ministério da Educação. Secretária de Educação Média e Tecnológica. Parâmetros curriculares nacionais: ensino médio. Brasília: Ministério da Educação, 1999.

ESTEBAN, M. T. Exames nacionais e subalternização das classes populares. In: REUNIÃO ANUAL DA ANPED, 31., 2008. CD-ROM.

FONSECA, R. A. S. ENEM - Exame Nacional do ensino Médio 1998-2007: olhares da escola pública mineira através da voz de gestores, pedagogos e professores de escolas da rede pública estadual de Passos (MG). 2010. 203f. Dissertação (Mestrado em Educação) - Programa de Pós-Graduação em Educação, Pontifícia Universidade Católica de Minas Gerais, Belo Horizonte, 2010.

FREITAS, D. N. T. A avaliação da educação básica no Brasil. Campinas: Autores Associados, 2007.

FREITAS, L. C. A avaliação e as reformas dos anos de 1990: novas formas de exclusão, velhas formas de subordinação. Educação e Sociedade, Campinas, v. 25, n. 86, p. 133-170, abril 2004.

FREITAS, L. C. Ciclos, seriação e avaliação: confrontos de lógicas. São Paulo: Moderna, 2003.

FREITAS, L. C. et. al. Avaliação educacional: caminhando pela contramão. 4. ed. Petrópolis: Vozes, 2012a.

FREITAS, L. C. et. al. Carta de Campinas. In: FREITAS, L. C. et. al. (Org.). Avaliação e políticas publicas educacionais: ensaios contrarregulatórios em debate. Campinas: Edições Leitura Crítica, 2012b.

Movimento, Porto Alegre, v. 20, n. 2, p. 819-840, abr./jun. de 2014. 
A Educação Física na escola do vestibular: as possíveis ...

GIL, A. C. Métodos e técnicas de pesquisa social. 5. ed. São Paulo: Atlas: 1999.

KOHL, H. G. Educação Física na educação básica e o novo ENEM: novos desafios e novas possibilidades. In: IV ENCONTRO DE ENSINO, PESQUISA E EXTENSÃO DA FACULDADE SENAC, 4., 2010, Recife. Anais... Recife: Senac, 2010. p. 1-5.

LOPES, A. C.; LOPEZ, S. B. A performatividade nas políticas de currículo: o caso do ENEM. Educação em Revista, Belo Horizonte, v. 26, n. 1, p. 89-110, abr. 2010.

LUCKESI, C. C. Avaliação da aprendizagem escolar: estudos e proposições. 19. ed. São Paulo: Cortez, 2008.

MELO, R. Z.; FERRAZ, O. L. O novo ensino médio e a Educação Física. Motriz, Rio Claro, v. 13, n. 2, p. 86-96, abr./jun. 2007.

MINAS GERAIS. Secretaria de Estado de Educação Física de Minas Gerais. Conteúdo Básico Comum: educação física, ensino fundamental e médio. Belo Horizonte: SEC Educação, 2005.

PARANÁ. Secretaria de Estado da Educação do Paraná. Diretrizes Curriculares da Educação Básica: educação física. Curitiba: Departamento de Educação Básica, 2008.

PERNAMBUCO. Secretaria de Educação do Governo de Pernambuco. Orientações Teórico-Metodológicas, ensino fundamental. ensino médio. Recife: SEE, 2008.

RIO GRANDE DO SUL. Secretaria de Estado da Educação. Departamento Pedagógico. (Org.). Referencias curriculares do estado do Rio Grande do Sul: linguagens, códigos e suas tecnologias. Porto Alegre: SE/DP, 2009.

SILVA, C. S. Estudo qualitativo sobre as mudanças que o ENEM - Exame Nacional do Ensino Médio provocou nos trabalhos pedagógicos e metodológicos dos professores do ensino médio. Espaço do Currículo, v. 4, n. 2, p. 186-196, mar. 2012.

SORDI, M. R. L.; LUDKE, M. Da avaliação da aprendizagem á avaliação institucional: aprendizagens necessárias. Avaliação, Campinas, v. 14, n. 2, p. 313336, jul. 2009.

SOUSA, S. M. Z. L. Possíveis impactos das políticas de avaliação no currículo escolar. Cadernos de Pesquisa, São Paulo, n. 119, p. 175-190, jul. 2003.

SOUZA JÚNIOR, M. B. M.; MELO, M. S. T.; SANTIAGO, M. E. Análise de conteúdo como forma de tratamento dos dados numa pesquisa qualitativa em Educação Física Escolar. Movimento, Porto Alegre, v. 16, n. 3, p. 31-49, jun./set. 2010.

ZANCHET, B. M. B. A. O exame nacional do ensino médio (ENEM): o que revelaram os professores do ensino médio acerca dessa avaliação. Contapontos, Itajaí, v. 7 , n. 1, p. 55-69, jan./abr. 2007.

ZANCHET, B. M. B. A. O exame nacional do ensino médio (ENEM): pressupostos conceituais e repercussões na prática pedagógica. In: CUNHA, M. I. (Org.). Formatos avaliativos e concepção de docência. Campinas: Autores Associados, 2005.

Movimento, Porto Alegre, v. 20, n. 2, p. 819-840, abr.jun. de 2014. 
Endereço para correspondência:

José Arlen Beltrão

Av. Nestor de Melo Pita, n. 535, Centro.

Centro de Formação de Professores - CFP/UFRB.

453000-000. Amargosa - BA.

Recebido em: 12.08.2013

Aprovado em: 27.02.2014

Movimento, Porto Alegre, v. 20, n. 2, p. 819-840, abr.jun. de 2014. 